\title{
Antimicrobial Effect of Kaempferol on Psychrotrophic Bacillus cereus Strains Outbreakable in Dairy Products
}

\author{
Kyoung Ah Lee ${ }^{1}$, Sun Hee Moon ${ }^{1}$, Kee-Tae Kim², Seung-Yeol Nah²,3, and Hyun-Dong Paik ${ }^{1,2, *}$ \\ ${ }^{1}$ Division of Animal Life Science, Konkuk University, Seoul 143-701, Korea \\ ${ }^{2}$ Bio/Molecular Informatics Center, Konkuk University, Seoul 143-701, Korea \\ ${ }^{3}$ Department of Physiology, College of Veterinary Medicine, Konkuk University, Seoul 143-701, Korea
}

\begin{abstract}
The objective of this study was to evaluate the antimicrobial effects of various natural flavonoids against growth of psychotropic Bacillus cereus strains, which cause dairy food outbreaks. Flavonoids were first screened for their ability to inhibit growth of $B$. cereus strains using the paper-disc diffusion test. Second, the growth inhibitory effect of selected flavonoids was evaluated in tryptic soy broth supplemented with $0.6 \%$ yeast extract, and the bactericidal effect of the flavonoids was measured in $0.8 \%(\mathrm{w} / \mathrm{v}) \mathrm{NaCl}$ solution. Based on the paper-disc diffusion test, kaempferol was effectively active against $B$. cereus $\mathrm{P} 14$ and $B$. cereus KCCM 40935. Kaempferol had an antimicrobial effect at concentrations greater than $100 \mu \mathrm{M}$, and the numbers of B. cereus P14 and B. cereus KCCM 40935 decreased by 3.55 and $1.5 \log$ cycles, respectively. The cell numbers of $B$. cereus P14 and B. cereus KCCM 40935 treated with $50 \mu \mathrm{M}$ kaempferol were reduced by 4.18 and 2.84 log cycles during a $24 \mathrm{~h}$ incubation to test the bactericidal effect of kaempferol $(p<0.05)$. The results indicate that kaempferol had the greatest antimicrobial effect among the psychotropic B. cereus strains and the natural flavonoids tested.
\end{abstract}

Key words: psychrotrophic Bacillus cereus, kaempferol, flavonoid, antimicrobial effect, dairy food

\section{Introduction}

Bacillus cereus is a gram positive, aerobic, spore-forming microorganism and a common cause of food poisoning (Andersson et al., 1995; Kramer et al., 1989). This species, which is a common soil inhabitant, is often present in foods such as rice, spices, milk and dairy products, vegetables, meats, cakes and other desserts (Granum, 2001). In particular, B. cereus is a contaminant of raw milk (Lin, 1998) and also frequently isolated from a variety of dairy products. Some psychrotrophic strains of $B$. cereus are known to grow in foods at temperatures as low as 4-6 ${ }^{\circ} \mathrm{C}$ (Dufrenne et al., 1994; Griffiths et al., 1990; Netten et al., 1990). This growth represents a problem in chilled products such as milk and other dairy products, and in ready-to-eat or fresh chilled foods. Generally, raw milk and dairy products are contaminated by $B$. cereus from the soil and grass (Andersson et al., 1995). The heat resistant spore-forming bacteria also pose a special prob-

\footnotetext{
*Corresponding author: Hyun-Dong Paik, Division of Animal Life Science and Bio/Molecular Informatics Center, Konkuk University, Seoul 143-701, Korea. Tel: 82-2-2049-6011, Fax: 82-2-2049-6011, E-mail: hdpaik@konkuk.ac.kr
}

lem for the food industry because it is not always possible to apply enough heat during food processing to kill the spores (Rowan et al., 1998; Borge et al., 2001).

Outbreaks of $B$. cereus are responsible for two types of food-borne illness such as the emetic and diarrheagenic syndromes (Granum et al., 1997). A variety of different enterotoxins have been characterized for each syndrome including hemolysin BL ( $\mathrm{Hbl})$, non-hemolytic enterotoxin (Nhe) (Agata et al., 1994; Agata et al., 1995; Yokoyama et al., 1999; Little et al., 1994).

Many researchers have studied about the antimicrobial effects of natural compounds extracted from medical plants toward B. cereus strains (Palombo et al., 2001). Flavonoids are natural organic compounds in fruits, flowers, stems, and roots. Flavonoids appear to have antimicrobial, anti-oxidative, anti-inflammatory, and anti-carcinogenic effects (Kim et al., 2005; Lee et al., 2006; Son et al., 2003), and have played major roles in successful medical treatments in ancient times as well as the present. In addition, there are numerous studies on the functional effects of flavonoids as health foods and pharmaceuticals (Aviram and Fuhrman, 2002; Bosetti et al., 2005; Joshipura et al., 1999). Therefore, the objective of this study was to evaluate in vitro the inhibitory effects of flavonoid on the 
growth of psychrotrophic B. cereus strains outbreakable in dairy products.

\section{Materials and Methods}

\section{Microorganisms}

B. cereus P14 was obtained from Pulmuone, Inc. (Seoul, Korea) and B. cereus KCCM 40935 was purchased from the Korea Culture Center of Microorganisms (KCCM; Seoul, Korea). The stock cultures were stored at $-70^{\circ} \mathrm{C}$ in tryptic soy broth (Difco Becton Dickinson, USA) with $15 \%$ glycerol and sub-cultured three times in $10 \mathrm{~mL}$ tryptic soy broth (Difco) supplemented with $0.6 \%$ yeast extract (TSB-YE) at $37^{\circ} \mathrm{C}$ for $12 \mathrm{~h}$.

\section{Flavonoids}

Eight different flavonoids were used in this study; the flavonols quercetin, and kaempferol; the flavones apigenin, luteolin, and 5, 4-dihydroxy-7-methoxyflavone (genkwanin); and the flavanones naringenin, hesperetin, and hesperidin. All flavonoids were purchased from Sigma Chemical Co. (USA) (Kim and Paik, 2008). All flavonoids were dissolved in dimethyl sulfoxide (DMSO) at appropriate concentrations for this study.

\section{Screening by paper disc diffusion method}

The paper disc diffusion method was used as a screening test for the antimicrobial activities of various flavonoids. Forty microliters of each flavonoid sample were applied to a paper disc ( $8 \mathrm{~mm}$ in diameter). The paper discs were placed on tryptic soy agar plates inoculated with $10^{6} \mathrm{CFU} / \mathrm{mL}$ of the $B$. cereus strain being tested. Discs were impregnated with $10 \mu \mathrm{L}$ of distilled water. The zone of inhibition was determined after incubation at $37^{\circ} \mathrm{C}$ for $16 \mathrm{~h}$ (Osawa et al., 1992).

\section{Measurement of antimicrobial effects}

The viable cell count method was used to test the effect of flavonoid on growth of B. cereus (Negi et al., 2002). The initial density of $B$. cereus was adjusted to $2.6 \times 10^{6}$ $\mathrm{CFU} / \mathrm{mL}$. One hundred microliters of B. cereus and 100 $\mu \mathrm{L}$ of flavonoid solution were added to $10 \mathrm{~mL}$ of tryptic soy broth (Difco Laboratories, USA) supplemented with $0.6 \%$ yeast extract (TSB-YE) followed by incubation at $37^{\circ} \mathrm{C}$. The flavonoid concentrations were adjusted to 25 , 50 , and $100 \mu \mathrm{M}$ in the final volume of broth. As a control, $100 \mu \mathrm{L}$ of DMSO was added to culture broth instead of flavonoid solution. The turbidities of the cell broths after incubation for $0,2,4,6$, and $8 \mathrm{~h}$ were measured at
$620 \mathrm{~nm}$ with a spectrophotometer (Optizen $2120 \mathrm{UV}$, Korea). The culture broths were also serially diluted in $0.1 \%$ peptone water and spread on tryptic soy agar (Difco Laboratories). After incubation at $37^{\circ} \mathrm{C}$ for $20 \mathrm{~h}$, the colonies were counted.

\section{Bactericidal effects of flavonoids on $\boldsymbol{B}$. cereus}

$B$. cereus was cultured in TSB-YE to a cell density of $2.6 \times 10^{6} \mathrm{CFU} / \mathrm{mL}$. The cell broths were then centrifuged at $10,000 \mathrm{~g}$ for $15 \mathrm{~min}$ at $4^{\circ} \mathrm{C}$ (Micro 17TR, Inchun, Korea). The cell sediments were washed in sterile $0.8 \%$ (w/v) $\mathrm{NaCl}$ solution and centrifuged at $10,000 \mathrm{~g}$ for 10 min at $4^{\circ} \mathrm{C}$. After washing twice, the cells were resuspended $5 \mathrm{~mL}$ of $0.8 \%(\mathrm{w} / \mathrm{v}) \mathrm{NaCl}$ solution and the cell density was adjusted to $2.6 \times 10^{6} \mathrm{CFU} / \mathrm{mL}$. The flavonoid concentrations tested were 25 , and $50 \mu \mathrm{M}$ in the final volume, and the suspensions were incubated for $0,2,4,8$, 12 , and $24 \mathrm{~h}$ at $37^{\circ} \mathrm{C}$ in a shaking incubator (SI-900R, JEIO-TECH, Korea) at $170 \mathrm{rpm}$ (Negi et al., 2002).

\section{Results and Discussion}

\section{Screening by paper disc diffusion method}

Use of the paper disc diffusion method is a very popular and useful method for screening new chemicals with antibacterial activities (Hong and Lee, 2001; Vuuren, 2008). The results of the paper disc diffusion test for 8 different flavonoids tested against several $B$. cereus strains are shown in Table 1. Kaempferol strongly inhibited the growth of B. cereus KCCM 40935, however, quercetin did not show antimicrobial activity toward any strains used in this study. Of the flavones tested, only apigenin had antimicrobial effects toward B. cereus P14 and $B$. cereus KCCM 40935, however, its antimicrobial activity was lower than that of kaempferol. Also, antimicrobial effect of apigenin was not correlated with concentration. As a results, antimicrobial effect of flavonoids differ according to the hydrophobicity, size of a molecule, and the position of their side chains on the flavonoid backbone structure (Martini et al., 2004).

\section{Antimicrobial effects of kaempferol on $B$. cereus P14 and B. cereus KCCM 40935}

Kaempferol was tested to evaluate antimicrobial effects on B. cereus P14 and B. cereus KCCM 40935. As shown in Fig. 1, 1\% DMSO in culture broth without kaempferol had no effect on B. cereus $\mathrm{P} 14$ and B. cereus KCCM 40935. For $B$. cereus $\mathrm{P} 14$, kaempferol had greater inhibitory effects at $100 \mu \mathrm{M}$, with decreases in cell number of 
Table 1. Growth inhibition of $B$. cereus $\mathrm{P} 14$ and $B$. cereus KCCM 40935

\begin{tabular}{|c|c|c|c|}
\hline Flavonoids & $\begin{array}{l}\text { Concentration } \\
(\mathrm{mM})\end{array}$ & $\begin{array}{l}\text { B. cereus } \\
\text { P14 }\end{array}$ & $\begin{array}{c}\text { B. cereus } \\
\text { KCCM } 40935\end{array}$ \\
\hline \multirow{4}{*}{ Kaempferol } & 2.5 & $-^{1)}$ & - \\
\hline & 5 & + & ++ \\
\hline & 10 & ++ & +++ \\
\hline & 20 & ++ & ++ \\
\hline \multirow{4}{*}{ Quercetin } & 2.5 & - & - \\
\hline & 5 & - & - \\
\hline & 10 & - & - \\
\hline & 20 & - & - \\
\hline \multirow{4}{*}{ Luteolin } & 2.5 & - & - \\
\hline & 5 & - & - \\
\hline & 10 & - & - \\
\hline & 20 & - & - \\
\hline \multirow{4}{*}{ Apigenin } & 2.5 & - & ++ \\
\hline & 5 & ++ & ++ \\
\hline & 10 & ++ & - \\
\hline & 20 & + & - \\
\hline \multirow{4}{*}{ Genkwanin } & 2.5 & - & - \\
\hline & 5 & - & - \\
\hline & 10 & - & - \\
\hline & 20 & - & - \\
\hline \multirow{4}{*}{ Naringenin } & 2.5 & - & - \\
\hline & 5 & - & - \\
\hline & 10 & - & - \\
\hline & 20 & + & - \\
\hline \multirow{4}{*}{ Hesperetin } & 2.5 & - & - \\
\hline & 5 & - & - \\
\hline & 10 & - & - \\
\hline & 20 & - & - \\
\hline \multirow{4}{*}{ Hesperidin } & 2.5 & - & - \\
\hline & 5 & - & - \\
\hline & 10 & - & - \\
\hline & 20 & - & - \\
\hline
\end{tabular}

${ }^{1)}$ No inhibition $(\leq 9 \mathrm{~mm}),+$ : slight inhibition (10-11.9 mm), ++: moderate inhibition $(12-13.9 \mathrm{~mm}),+++$ : strong inhibition $(\geq 14$ $\mathrm{mm})$.

$3.5 \log$ cycles during the incubation time for $8 \mathrm{~h}(p<0.05)$. In case of B. cereus KCCM 40935, the numbers of cells treated with kaempferol were decreased with about 1.5 $\log$ cycles.

\section{Bactericidal effects of kaempferol on B. cereus P14} and B. cereus KCCM 40935

The bactericidal effects of kaempferol at 25 , and $50 \mu \mathrm{M}$ concentrations against both $B$. cereus $\mathrm{P} 14$ and B. cereus
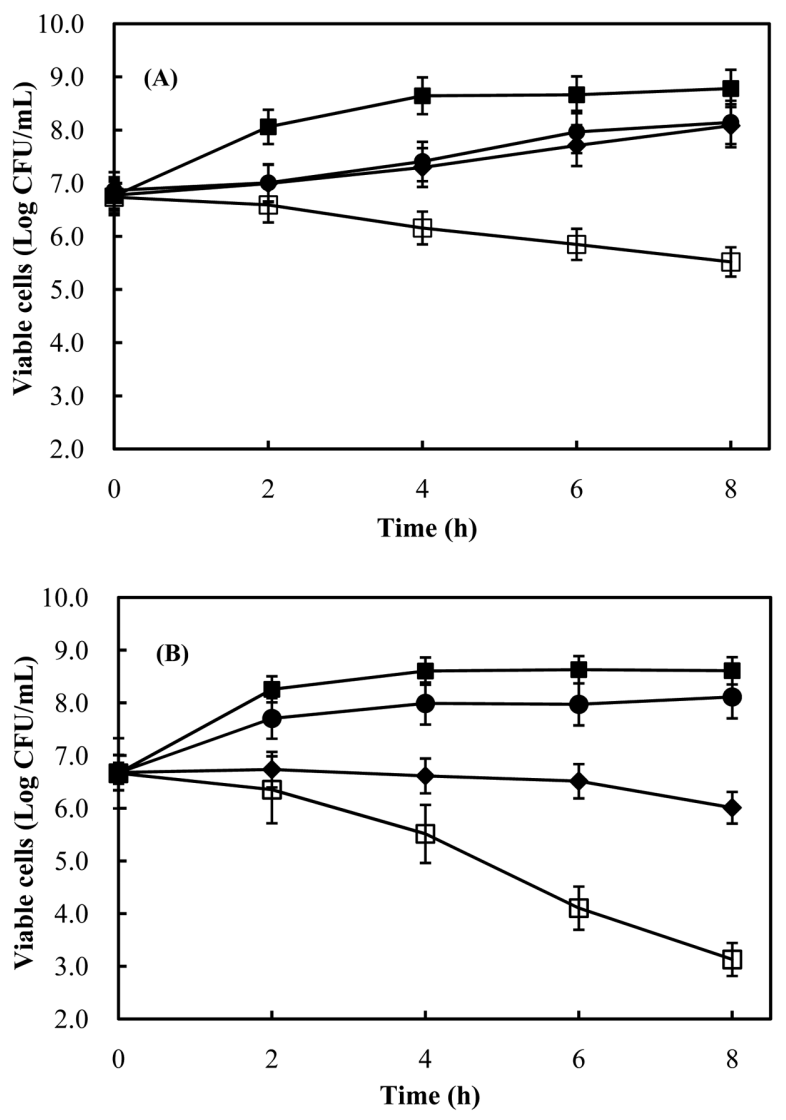

Fig. 1. Growth inhibition of kaempferol on B. cereus P14 and B. cereus KCCM 40935. The initial number of cells was adjusted to be $2.6 \times 10^{6} \mathrm{CFU} / \mathrm{mL}$ and the concentrations of flavonoids were adjusted to $25 \mu \mathrm{M}(\bullet), 50 \mu \mathrm{M}(\bullet), 100$ $\mu \mathrm{M}(\square)$. The control (ם) contained DMSO only. (A), $B$. cereus P14; (B), B. cereus KCCM 40935.

$\mathrm{KCCM} 40935$ in $0.8 \%(\mathrm{w} / \mathrm{v}) \mathrm{NaCl}$ solutions were tested. As shown in Fig. 2, it appeared that the numbers of survival cells were significantly reduced at $50 \mu \mathrm{M}$ concentration of kaempferol. B. cereus $\mathrm{P} 14$ and B. cereus KCCM 40935 were decreased with $4.18 \log$ cycles and $2.84 \log$ cycles after $24 \mathrm{~h}$, respectively $(p<0.05)$.

It is known that flavonoids affect the growth of many, but not all, microorganisms and their use for inhibiting microbial growth has two purposes: i) to kill prokaryotic or eukaryotic cells, or to inhibit their growth and ii) to decrease their spread and the effects of their toxins. Although the mechanisms by which this is accomplished are not yet known, it involves the inhibition of nucleic acid synthesis, cytoplasmic membrane function, and energy metabolism (Tim and Lamb, 2005). Based on the results of this study, kaempferol has a great antimicrobial effect on psychrotrophic $B$. cereus strains, however, the detailed mechanisms and kinetics of their antimicrobial effects are as yet unknown because the effect of flavonoids on infec- 

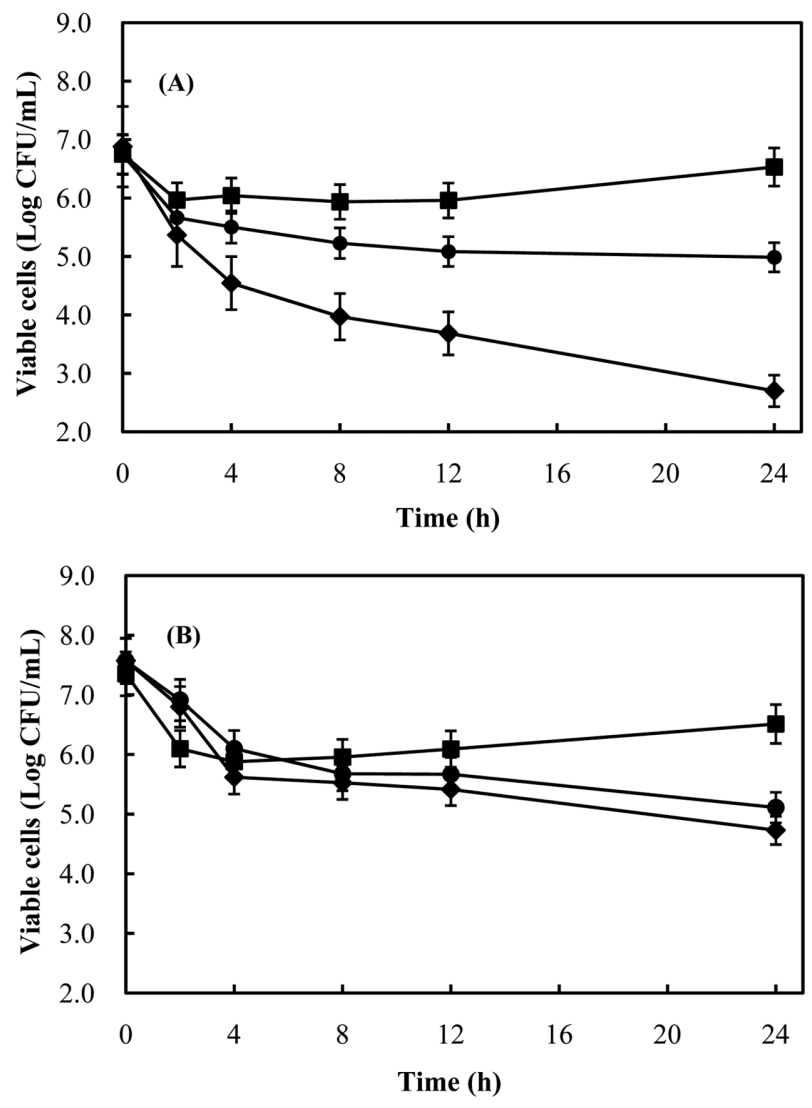

Fig. 2. Bactericidal effect of kaempferol on B. cereus P14 and B. cereus $\mathrm{KCCM} 40935$ in $0.8 \% \mathrm{NaCl}$ solution. Initial cell density was adjusted to $2.6 \times 10^{6} \mathrm{CFU} / \mathrm{mL}$. Flavonoid concentrations were adjusted to $25 \mu \mathrm{M}(\bullet), 50 \mu \mathrm{M}(\bullet)$. The control (ם) contained DMSO only. (A), B. cereus P14; (B), B. cereus KCCM 40935.

tious agents involves many potential targets in cells and is very complicated as mentioned above. Kaempferol exist in various plants such as tea, broccoli, propolis, and other plants source. It has an effect on anticancer and cytotoxic effects

Therefore, kaempferol shows as a potential natural preservative for the raw milk and dairy products. In the further work, the antimicrobial effect of kaempferol in food system and activity of flavonoids on the sporulation or germination of $B$. cereus strains in raw milk or dairy products should be studied.

\section{Acknowledgments}

This work was supported by ARPC grant \#109117-031-HD120 and Priority Research Centers Program through the National Research Foundation of Korea (NRF) funded by the Ministry of Education, Science and Technology (2009-0093824), and also supported by the Konkuk University.

\section{References}

1. Agata, N., Mori, M., Ohta, M., Suwan, S., Ohtani, I., and Isobe, M. (1994) A novel dodecadepsipeptide, cereulide, isolated from Bacillus cereus vacuole formation in HEp-2 cells. FEMS Microbiol. Lett. 121, 31-34.

2. Agata, N., Ohta, M., Mori, M., and Isobe, M. (1995) A novel dodecadepsipeptide, cereulide, is an emetic toxin of Bacillus cereus. FEMS Microbiol. Lett. 129, 17-20.

3. Andersson, A., Ronner, U., and Granum, P. E. (1995) What problems does the food industry have with the spore-forming pathogens Bacillus cereus and Clostridium perfringens? Int. J. Food Microbiol. 28, 145-155.

4. Aviram, M. and Fuhrman, B. (2002) Wine flavonoids protect against LDL oxidation and atherosclerosis. Ann. NY Acad. Sci. 957, 146-161.

5. Borge, G. I. A., Skeie, M., Sorhaug, T., Langsrud, T., and Granum, P. E. (2001) Growth and toxin profiles of Bacillus cereus isolated from different food sources. Int. J. Food Microbiol. 69, 237-246.

6. Bosetti, C., Spertini, L., Parpinel, M., Gnagnarella, P., Lagiou, P., Negri, E., Franceschi, S., Montella, M., Peterson, J., Dwyer, J., Giacosa, A., and La, V. C. (2005) Flavonoids and breast cancer risk in Italy. Cancer Epidemiol. Biomarkers Prev. 14, 805-808.

7. Dufrenne, J., Soentoro, P., Tatini, S., Day, T., and Notermans, S. (1994) Characteristics of Bacillus cereus related to safe food production. Int. J. Food Microbiol. 23, 99-109.

8. Granum, P. E. (2001) Bacillus cereus. In: Doyle, M.P., Beuchat, L. R., and Montville, T. J. (eds.) Food Microbiology. Fundamentals and Applications, 2nd ed, ASM Press, Washington, DC. 373-381.

9. Granum, P. E. and Lund, T. (1997) Bacillus cereus and its food poisoning toxins. FEMS Microbiol. Lett. 157, 223-228.

10. Griffiths, M. W. and Phillips, J. D. (1990) Incidence, source and some properties of psychrotrophic Bacillus spp. found in raw and pasteurized milk. Int. J. Dairy Technol. 43, 62-66

11. Hong, X. X. and Lee, S. F. (2001) Activity of plant flavonoids against antibiotic resistant bacteria. Phytother. Res. 15, 39-43.

12. Joshipura, K. J., Ascherio, A., Manson, J. E., Stampfer, M. J., Rimm, E. B., Speizer, F. E., Hennekens, C. H., Spiegelman, D., and Willett, W. C. (1999) Fruit and vegetable intake in relation to risk of ischemic stroke. J. Am. Med. Assoc. 282, 1233-1239.

13. Kim, K.-T. and Paik, H.-D. (2008) Propolis as a multi-functional natural material for health. In: Natural products as future medicinal agents. Hawthorne S. (ed) Transworld Research Network, Kerala, India. pp. 33-48.

14. Kim, K.-T., Yeo, E. J., Han, Y. S., Nah, S. Y., and Paik, H.-D. (2005) Antimicrobial, anti-inflammatory, and anti-oxidative effect of water and ethanol extracted Brazilian propolis. Food Sci. Biotechnol. 14, 474-478.

15. Lee, Y. J., Kim, B. G., Park, Y. H., Lim, Y. H., Hur, H. G., and Ahn, J. H. (2006) Biotransformation of flavonoids with $O$ methytransferase from Bacillus cereus. J. Microbiol. Bio- 
technol. 16, 1090-1096.

16. Lin, S., Schraft, H., Odumeru, J. A., and Griffiths, M. W. (1998) Identification of contamination sources of Bacillus cereus in pasteurized milk. Int. J. Food Microbiol. 43, 159171.

17. Little, C. L. and Knochel, S. (1994) Growth and survival of Yersinia enterocolitica, Salmonella and Bacillus cereus in brie stored at 4,8 and $20^{\circ}$ C. Int. J. Food Microbiol. 24, 137145.

18. Martini, N. D., Katerere, D. R. P., and Eloff, J. N. (2004) Biological activity of five antibacterial flavonoids from Combretum erythrophyllum (Combretaceae). J. Ethnopharmacol. 93, 207-212.

19. Negi, P., John, S. K., and Rao, P. U. (2002) Antimicrobial activity of mango sap. Eur. Food Res. Technol. 214, 327-330.

20. Netten, P., Moosdijk. A., Hoensel, P., Mossel, D. A., and Perales, I. (1990) Psychrotrophic strains of Bacillus cereus producing enterotoxin. J. Appl. Bacteriol. 69, 73-79.

21. Osawa, K., Yasuda, H., Maruyama, T., Morita, H., Takeya, K., and Itokawa, H. (1992) Isoflavanones from the heartwood of Swartzia polyphylla and their antibacterial activity against cariogenic bacteria. Chem. Pharm. Bull. (Tokyo) 40,
2970-2974.

22. Palombo, E. A. and Semple, S. J. (2001) Antibacterial activity of traditional Australian medical plants. J. Ethnopharmacol. 77, 151-157.

23. Rowan, N. J. and Anderson, J. G. (1998) Diarrhoeal enterotoxin production by psychrotrophic Bacillus cereus present in reconstituted milk-based infant formulae (MIF). Lett. Appl. Microbiol. 26, 161-165.

24. Son, D. J., Lee, S. E., and Park, B. S. (2003) Inhibitory effects of naturally occurring flavonoids on a human intestinal bacterium, Clostridium botulinum. Food Sci. Biotechnol. 12, 180-182.

25. Tim, C. T. P. and Lamb, A. J. (2005) Antimicrobial activity of flavonoids. Int. J. Antimicrob. Agents 26, 343-356.

26. Vuuren, S. F. (2008) Antimicrobial activity of South African medicinal plants. J. Ethnopharmacol. 119, 462-472.

27. Yokoyama, K., Ito, M., Agata, N., Isobe, M., Shibayama, K., Horii, T., and Ohta, M. (1999) Pathological effect of synthetic cereulide, an emetic toxin of Bacillus cereus is reversible in mice. FEMS Immunol. Med. Microbiol. 24, 115-120.

(Received 2010.12.30/Revised 2011.3.10/Accepted 2011.3.24) 